\title{
Characterization and Application of Naturally Occurring Mineral Based Pigment in Surface Coating
}

\author{
Shweta Umale, Prakash Mahanwar \\ Department of Polymer and Surface Engineering, Institute of Chemical Technology, Mumbai, India \\ Email: sonaumale@gmail.com
}

Received July 8, 2012; revised August 13, 2012; accepted August 27, 2012

\begin{abstract}
New naturally occurring mineral based pigment of general formula $\mathrm{Hg}_{2} \mathrm{~S}$ have been processed and characterized for its application in surface coating. Various analytical protocol like XRD, FT-IR, SEM and CIE 1976 colour coordinate system have been performed for complete analysis of pigment. Characterizations using XRD, and CIE 1976 colour coordinate assessment reveal the formation of pigments displaying colours ranging from brick-red to dark-brown. The typical designed pigment samples have been evaluated for their mass tone/hiding power, tinting strength and weather resistance by coating on an MS steel panel. Optical, Chemical, Mechanical and performance properties of coating have been evaluated for its application. The results demonstrated that the dark-brown pigment obtained in the present study was found to be an interesting alternative to the existing classical toxic inorganic red pigments for surface coating applications.
\end{abstract}

Keywords: Light Fastness; Colour Value; Surface Coating; Dispersability; Refractive Index

\section{Introduction}

Natural inorganic pigments have been known since prehistoric times, for example the drawings in the PechMerle caves in the south of France, Northern Spain, and Northern Africa were made with charcoal, ochre, manganese brown and clays [1,2]. About $2000 \mathrm{BC}$, natural ochre was burnt, sometimes in mixtures with manganese ores, to produce red, violet, and black pigments for pottery [3]. Arsenic sulphide and Naples yellow (a lead antimonate) were the first clear yellow pigments. Ultramarine and artificial lapis lazuli (Egyptian blue and cobalt aluminium spinel) were the first blue pigments [4].

Cinnabar is red color pigment which can be largely used in surface coating application but there is large controversy on utilization of mercury containing pigment. But Mercury in traditional Chinese medicines mainly comes from cinnabar, deliberately included for therapeutic purposes based on Pharmacopeia of China [5]. Chinese Ministry of Health has paid close attention to the mercury contents in traditional Chinese remedies. The allowable amounts of cinnabar in these preparations have been decreased by as much as $65 \%$, from a daily allowable dose of $0.3-1.5 \mathrm{~g}$ in the 1977 Pharmacopeia to $0.1-0.5 \mathrm{~g}$ in the 2005 Pharmacopeia of China [6], but the mercury in these traditional medicines can still be thousands-folds higher than what is considered safe in Western countries including the USA The analysis showed that cinnabar is insoluble and poorly absorbed from the gastrointestinal tract [7-10]. Absorbed mercury from cinnabar is mainly accumulated in the kidneys, resembling the disposition pattern of inorganic mercury [11-13].

Use of inorganic pigments are paints, plastics, printing inks for paper and textiles, leather decoration, building materials, floor coverings, rubber, cosmetics, ceramic glazes and enamels. When choosing a pigment for a particular application, several points normally have to be considered [14-16]. The coloring properties are important in determining the application efficiency and hence economics. The following properties are also important:

1) General chemical and physical properties: Chemical composition, moisture and salt content, content of water soluble and acid soluble matter, particle size, density and hardness.

2) Stability properties: Resistance towards light, weather, heat and chemicals, anticorrosive properties and retention of gloss.

3) Behaviour in binders: Interaction with the binder properties, Dispersability, compatibility and solidifying effect.

So the main objectives of this study was

1) To process and characterize mineral based pigment collected from geographical place.

2) To study physico-chemical properties of the pigment.

3) To formulate paint by using same pigment and to study performance properties of the pigment. 


\section{Material and Methods}

The material was obtained from various Geographical places; it is of red colour type (Figure 1). For convenience red colored sample is referred as (RS). The sample was crushed by using mortar and pestle and then ground so as to obtain fine powder. The powder material was then ball milled to convert into fine powder. Particle size was determined by using particle size analyzer. Various analytical protocols have been used for material identification such as X-ray diffraction, FT-IR, Scanning electron microscope (SEM-EDX) and Differential Scanning colorimetry (DSC). XRD analysis of samples shows the presence of certain amount of mineral phases. An elemental analysis can be performed by using energy dispersive X-ray fluorescence. The physico-chemical properties were studied.

\subsection{Characterization and Testing}

\subsubsection{Oil Absorption Value (ASTM D 281-31)}

Oil absorption value as per ASTM D281-31 was evaluated using alkali linseed oil. Oil absorption value is expressed as mg of oil/100 gm of pigment. Pigment type, pigment size, and particle size distribution these are the factors which affect oil absorption value.

\subsubsection{Moisture content of pigment (ASTM D 280-75)}

Moisture content refers to the water left in the pigment after it has dried. Generally, the moisture present account for a very small fractions and is mainly due to the water entrapped within different particles of pigment. Here, a known weight of a pigment is dried in an oven at $105^{\circ} \mathrm{C}$ for $2 \mathrm{hrs}$. From the loss in weight, the moisture content is determined.

\subsubsection{Bleeding of Pigments (ASTM D 279-02)}

Bleeding is the term used to describe the discoloration or staining which sometime occurs when a white or light coloured paint is applied over a deeper colour. Bleeding property of pigment is evaluated as per ASTM D 279-02. Pigment is tested for toluene, Xylene, Butanol and MEK.

\subsubsection{Hiding Power of Paint (ASTM D 344-97)}

Hiding power of pigment was evaluated according to

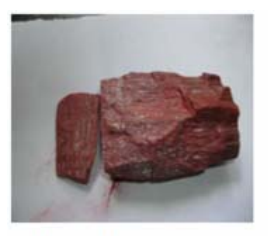

Mineral

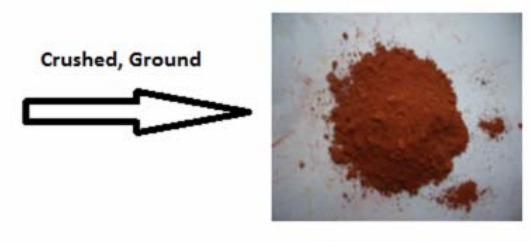

Mineral based pigment
Figure 1. Photographs of red pigment collected from geographical place.
ASTM D 344-97. Chequers board with alternative black and white blocks was used for testing. Pigment was dispersed in medium and then applied on board. Amount required to hide the measured space is calculated.

\subsubsection{Resistance to Heat (IS: 3493)}

Resistance to heat of pigment was evaluated according to IS 3493. Heat resistance was tested up to $180^{\circ} \mathrm{C}$.

\subsubsection{Density (ASTM D 13)}

Specific gravity of pigment was determined according to ASTM D 13.

\subsubsection{Formulation of Paint by Using RS}

Paint was formulated by using pigment RS. Various batches of paint were formulated by varying pigment volume concentration. Each batch was characterized for its solid content, drying time, gloss and skinning properties. The detailed material data sheet is mentioned in Table 1. The components of formulation are mentioned in Table 2. The characterization of each batch is given in Table 3 .

\subsection{Performance Properties of Coating}

Four coating formulation panels (F1, F2 and F3) were tested for different mechanical and chemical resistance properties as per the following standard test methods. The coated panel with formulation is shown in Figure 2.

Table 1. Material data.

\begin{tabular}{cc}
\hline Product name & Raplakyd-515-60) \\
\hline Solvent & $60 \pm 2$ \\
General ingredient & Mineral Turpentine \\
Oil length (\%) & Linseed oil penta \\
Acid value (max) (mgs. of & 64 \\
KOH/gm) & $100^{\circ} \mathrm{C}$ \\
$\begin{array}{c}\text { Dilution solvent } \% \text { for testing } \\
\text { color \& viscosity } \\
\text { Color (Gardner) }\end{array}$ & 7 \\
\hline
\end{tabular}

Table 2. Formulation 1.

\begin{tabular}{ccc}
\hline Raw material & Part by wt & wt $\%$ \\
\hline Binder (raplakyd-515-60) & 12 & 52 \\
Pigment (RSO) & 5 & 22 \\
Solvent (MTO) & 5 & 22 \\
W \& D agent & 0.2 & 8.8 \\
Antisettling agent & 0.1 & 4.4 \\
Drier & 0.1 & 4.4 \\
\hline
\end{tabular}


Table. 3 Characterization of batch.

\begin{tabular}{cc}
\hline PVC- & 15.25 \\
\hline Vehicle non-volatile- & $60 \%$ \\
Brushing - & Excellent \\
Levelling- & Very good \\
Settling- & Hard \\
Skinning- & High \\
Gloss- & High \\
Drying time & Touch dry $-4-5 \mathrm{hrs}$ \\
& Hard dry-9 - $10 \mathrm{hrs}$ \\
\hline
\end{tabular}

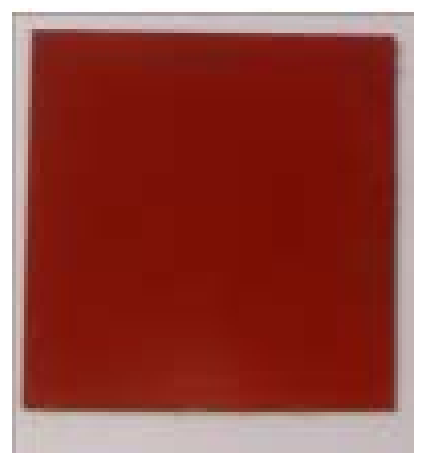

Figure 2. Photograph of painted MS panels with pigment.

\subsubsection{Scratch Hardness}

Scratch hardness was carried out as per ASTM D-2197. The scratch resistance of the samples was determined using an automatic scratch hardness tester having a hard end steel hemispherical point of $1 \mathrm{~mm}$ diameter as a scratching needle. The test was moved at a fixed speed of $3 \mathrm{~cm} / \mathrm{sec}$ beneath the point of scratching needle. The scratch resistance is reported as the weight on the stylus to tear off the coating. This test simulates scratching by sharp objects.

\subsubsection{Pencil Hardness}

Pencil hardness of coating was determined as per ASTM D 3363 using pencil hardness tester with calibrated set of drawing leads ranging from $\mathrm{B}$ (the softest) to $6 \mathrm{H}$ (the hardest). The process was started with softest pencil to end with hardest pencil. A scratch hardness value of the films is equal to the hardness value of the pencil that tear the film.

\subsubsection{Impact Resistance}

Tubular impact resistance test was conducted as per ASTM D2794 to predict the ability of the coating to resist cracking caused by rapid deformation. It is reported in terms of inch-pound (height-load). Tubular impact resistance test was carried out using an indenter with hemispherical head of diameter 0.625 inch and $2 \mathrm{lb}$ load.

\subsubsection{Flexibility}

The Conical Mandrel Bend Test of the coatings was carried out as per ASTM D522. The Mandrel Bend Test is a measure of flexibility of coating. As applied coat was dried enough the prepared panels were kept between the mandrel and draw bar. The lever bar was drawn down at uniform velocity to bend the specimen approximately of $135^{\circ}$. The bent surface was observed for crack or other surface defects.

\subsubsection{Cross-Hatch Adhesion}

This test carried out as per ASTM D3359-83. Crosscut adhesion tape test is used to assess the adhesion of coating films to metallic substrates. Cuts were made on the coating in one steady motion with sufficient pressure on the cutting tool having a cutting edge angle between $15^{\circ}$ and $30^{\circ}$. After making two such cuts at $90^{\circ}$ the grid area was brushed and a $2.5 \mathrm{~cm}$ wide semi-transparent pressure-sensitive adhesive tape was placed over the grid. After 30 seconds of application, the tape was removed rapidly and the grid was inspected according to the standards. The amount of coated area retained under the tape corresponds to the adhesion efficiency of the coating. More the coated material removed by the tape, poorer the adhesion of the coating to the substrate.

\subsubsection{L, A, B Values}

The $\mathrm{L}^{*}, \mathrm{a}^{*}, \mathrm{~b}^{*}$ values of the pigment system were evaluated by using colour Eye 7000 spectrophotometer with CIELab colour coordinate system.

\subsubsection{Chemical Properties}

Resistance to acid and alkali was determined by using ASTM D-4274-88 standard while for detergent resistance standard ASTM D-2248a was followed. For this test, the coated panels were immersed in 5\% solution of HCL (acid), 5\% solution of $\mathrm{NaOH}$ (alkali) and 5\% solutionof detergent. The immersed panels were maintained at constant temperature. The panels were removed for examination after $6,12,18$ and 24 hours from the start of the test and observed for loss of adhesion, blistering, popping or any other deterioration of the film.

\subsubsection{Solvent Resistance}

The resistance of the coating towards the solvents like Methyl Ethyl Ketone (MEK) and xylene was determined as per the procedure given in ASTM D-5402-93. The coated panels were rubbed with the cotton moist with respective solvent and observed for any softness of the film, peeling of the film and loss of gloss.

\subsection{Optical Properties}

\subsubsection{Gloss}

Gloss is a measure of ability of coated surface to reflect 
light at a particular angle without scattering. Gloss was determined according to ASTM D523-67. Gloss of the cured sample was measured at angles $45^{\circ}$ and $60^{\circ}$ using a digital mini gloss meter calibrated against internal standard i.e. refractive index (Komal Scientific Co. Mumbai, India) and the results are reported in terms of gloss unit (GU).

\subsubsection{Colour Values}

$\mathrm{L}^{*}, \mathrm{a}^{*}$ and $\mathrm{b}^{*}$ values were calculated as per the CIE 1976 method. The $\mathrm{L}^{*}, \mathrm{a}^{*}$ and $\mathrm{b}^{*}$ values of coating were determined using spectrophotometer. (Gretag Macbeth, ColourEye-7000A, USA). L ${ }^{*}$ determines the lightness or darkness (higher the $\mathrm{L}^{*}$ value, higher is the lightness and vice versa), $a^{*}$ gives the redness or greenness $\left(+v e a^{*}=\right.$ redness and $-v e a^{*}=$ greenness) and $b^{*}$ indicates the yellowness or blueness $\left(+\mathrm{ve} \mathrm{b}^{*}=\right.$ yellowness and $-\mathrm{ve} \mathrm{b}^{*}=$ blueness).

\subsubsection{UV Resistance}

QUV accelerated weathering tester of Q-panel lab products was used for weather ability testing. The panels were kept in the weathering tester to study the weathering resistance of the coatings. This test is conducted according to ASTM G 154. The test was done in two alternate cycles provided with 4 hours of UV radiation and 4 hours of condensation as per the standard. The samples were tested for the optical properties to observe the change in colour values. During the accelerated weathering, the surface colour difference of the sample was measured in order to record photochemical degradation. The surface colour difference $\left(\Delta \mathrm{E}^{*}\right)$ was measured using colour spectrophotometer and it was calculated using CIE L ${ }^{*} a^{*} b^{*}$ system.

$$
\begin{aligned}
& \Delta \mathrm{L}^{*}=\mathrm{L}_{\mathrm{f}}{ }^{*}-\mathrm{L}_{\mathrm{i}}{ }^{*} \\
& \Delta \mathrm{a}^{*}=\mathrm{a}_{\mathrm{f}}{ }^{*}-\mathrm{a}_{\mathrm{i}}{ }^{*} \\
& \Delta \mathrm{b}^{*}=\mathrm{b}_{\mathrm{f}}{ }^{*}-\mathrm{b}_{\mathrm{i}}{ }^{*}
\end{aligned}
$$

$L^{*}, a^{*}$ and $b^{*}$ represent the lightness, redness and yellowness, respectively.

$$
\Delta \mathrm{E}^{*}=\left(\Delta \mathrm{L}^{* 2}+\Delta \mathrm{a}^{* 2}+\Delta \mathrm{b}^{* 2}\right)^{1 / 2}
$$

$\Delta \mathrm{L}^{*}, \Delta \mathrm{a}^{*}$ and $\Delta \mathrm{b}^{*}$ represent the difference between the initial (i) and present (f) values.

\section{Result and Discussion}

\subsection{Charactrization}

\subsubsection{XRD Analysis}

XRD pattern of the material shows intense and sharp peaks which reveal the crystalline nature of pigment Figure 3. The data obtained from diffract grams was then analyzed for reflection angle to calculate the interatomic spacing (D value in Angstrom units). The intensity is measured to discriminate various $\mathrm{D}$ spacing and the result was compared with standard mineral data to identify possible matches.

\subsubsection{Elemental analysis}

Elemental analysis of pigment was performed by inductively coupled plasma-atomic emission spectroscopy (ICP-AES) and Energy Dispersive X-ray fluorescence (EDX). Result shows that pigment contain mercury as major constituent in the form of mercury sulphide.

\subsubsection{SEM Analysis of Sample}

The morphology of the material was analyzed by using SEM and were found to be more or less uniform Figure 4. The crystalline nature of pigments has also been noticed from SEM micrograph of pigment. SEM micrograph of the sample shows that surface of pigment is irregular and shows cristae.

\subsubsection{FT-IR Spectrum of Pigment}

FT-IR spectrum of pigment Figure 5 shows that no characteristic peak was observed in the spectrum indicating no organic functionality.

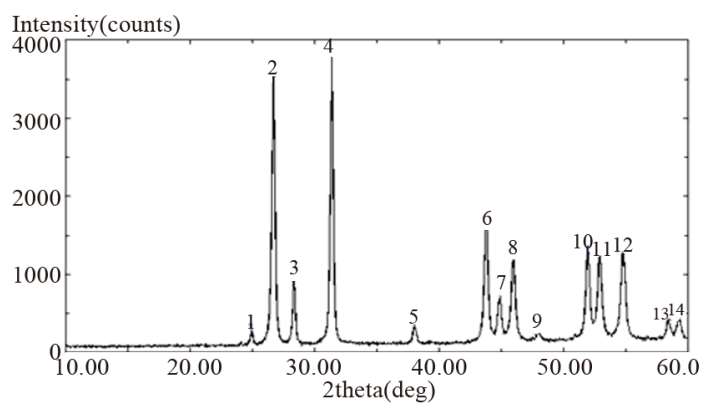

Figure 3. XRD pattern of pigment.

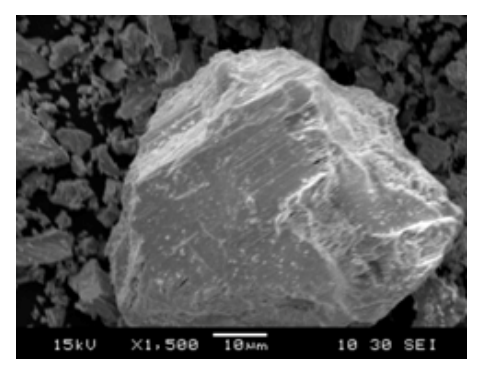

Figure 4. SEM micrograph of pigment.

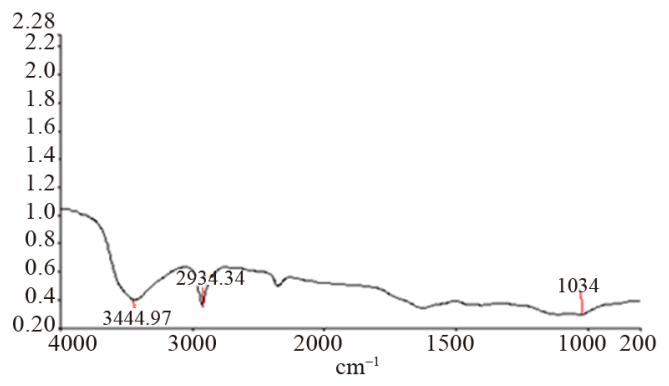

Figure 5. FT-IR spectrum of sample. 


\subsubsection{Physicochemical Properties of Pigments}

Physic-chemical properties of the pigment are mentioned in the following Table 4. Which indicate that pigment has excellent acid resistance but poor alkali resistance? The pigments do not show bleeding in organic solvents. They are neutral in nature. The oil absorption value of this pigment is in the acceptable range considering the inorganic nature of pigment.

\subsection{Performance Properties of Paint by Red Colour Pigment}

\subsubsection{Mechanical Properties}

The results of scratch resistance, pencil hardness, impact resistance, flexibility, cross hatch adhesion for coating formulations Figures $\mathbf{1}$ to $\mathbf{1 0}$ are shown in Table 5. From the table it is clear that impact resistance of paint is good. The flexibility test was passed for all the pigment coating. Cross hatch adhesion by tape was determined by applying cross cuts on the coated panel. All the coating formulations passed across hatch adhesion test. Gloss of lacquer coating was compared with gloss of Figures 1 to 3 at 45 and 60 . Gloss of formulation 1, 2 and 3 is higher than lacquer. Result shows that in both the cases gloss increases after dispersing pigment in lacquer. Improvements in properties are attributed to surface characteristics of pigment.

Table 4. Physico-chemical properties of the pigment.

\begin{tabular}{cc}
\hline Parameter & Inference \\
\hline Oil absorption value & $29.7 \mathrm{mg} / 100 \mathrm{~g}$ pig. \\
Particle size & $30-50 \mathrm{micron}$ \\
Density & $2.66 \mathrm{~g} / \mathrm{cm}^{3}$ \\
Chemical nature & Neutral \\
Chemical resistance & Acid-good \\
Alkali-good \\
Toluene-excellent \\
Xylene-excellent \\
Butanol-excellent \\
Bleeding properties
\end{tabular}

Table 5. Mechanical properties of pigment.

\begin{tabular}{ccccccccccc}
\hline & F1 & F2 & F3 & F4 & F5 & F6 & F7 & F8 & F9 & F10 \\
\hline $\begin{array}{c}\text { Impact } \\
\text { resistance }\end{array}$ & $\mathrm{P}$ & $\mathrm{P}$ & $\mathrm{P}$ & $\mathrm{P}$ & $\mathrm{P}$ & $\mathrm{P}$ & $\mathrm{P}$ & $\mathrm{P}$ & $\mathrm{P}$ & $\mathrm{P}$ \\
$\begin{array}{c}\text { Flexibility } \\
\begin{array}{c}\text { Pencil } \\
\text { Pendness }\end{array}\end{array}$ & $\mathrm{P}$ & $\mathrm{P}$ & $\mathrm{P}$ & $\mathrm{P}$ & $\mathrm{P}$ & $\mathrm{P}$ & $\mathrm{P}$ & $\mathrm{P}$ & $\mathrm{P}$ & $\mathrm{P}$ \\
$\begin{array}{c}\text { Scratch } \\
\text { hardness } \\
\text { (g) }\end{array}$ & 200 & 300 & 300 & 300 & 300 & 300 & 300 & 300 & 300 & 300 \\
$\begin{array}{c}\text { Gloss at } \\
60^{\circ}\end{array}$ & 78 & 73 & 89 & 71.68 & 70 & 71 & 68 & 67 & 68 & 70 \\
$\begin{array}{c}\text { Gloss at } \\
45^{\circ}\end{array}$ & 51 & 36 & 45 & 45 & 48 & 52 & 55 & 52 & 51 & 49 \\
\hline
\end{tabular}

\subsubsection{Chemical Resistance}

The coating samples were tested for their chemical resistance properties. The results of the tests are shown in Table 6. Chemical inertness of pigment protects the surface from various chemicals \& reagents thereby resulting in improvement in overall chemical \& solvent resistant properties. It was observed that acid has caused loss in adhesion resulting in partial peeling off the coating also alkali causes blistering of paint film. Film shows good chemical resistance against organic solvents.

\subsubsection{Optical Properties}

The coated panels were tested for the accelerated weathering testing up to 400 hours of exposure. During this after every 100 hours gloss and colour values of the tested panels were determined. From the $\mathrm{L}^{*}, \mathrm{a}^{*}$ and $\mathrm{b}^{*}$ values the discoloration measurement is done by calculating $\Delta \mathrm{E}^{*}$ value. Table 7 shows the discoloration value for the paint coating. We studied change in colour values with respect to hours exposed for coatings. Result shows that there is no drastic change in color values after exposure to Quv weatherometer indicating good light fastness. The color values of natural pigment were compared with synthetic pigment (red iron oxide) shown in Table 8. A lower value of $\mathrm{DE}^{*}$ i.e., 15.12 indicate that natural pigment has similar mass tone to that of synthetic pigment and can replace synthetic one.

Table 6. Chemical resistance of coating.

\begin{tabular}{cccc}
\hline Property & F1 & F2 & F3 \\
\hline Acid Resistance & 4 & 5 & 5 \\
Alkali Resistance & 1 & 3 & 3 \\
$\begin{array}{c}\text { Distilled water Resis- } \\
\text { tance }\end{array}$ & 1 & 1 & 1 \\
$\begin{array}{c}\text { Detergent Resistance } \\
\text { Solvent Re- MEK }\end{array}$ & 1 & 1 & 1 \\
sistance xylene & 1 & 1 & 1 \\
\hline
\end{tabular}

${ }^{1}$ Not affected, ${ }^{2}$ Loss in gloss, ${ }^{3}$ Blistering, ${ }^{4}$ Slight loss of adhesion, ${ }^{5}$ Film partially removed, ${ }^{6}$ Film completely removed

Table 7. $L^{*}$, $a^{*}$ and $b^{*}$ values for paint system during the accelerated weathering.

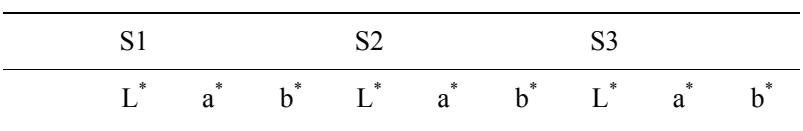

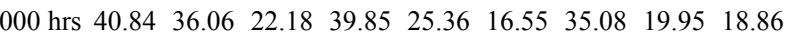

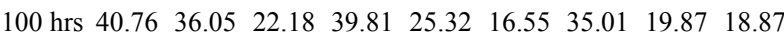

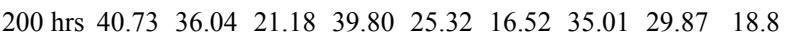

$\begin{array}{llllllllll}300 \mathrm{hrs} & 39.73 & 36.04 & 21.18 & 40.20 & 25.32 & 16.52 & 35.01 & 29.87 & 18.8\end{array}$

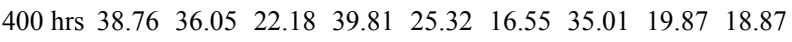




\subsubsection{Evaluation of Mass Tone/Hiding Power of Pigment}

The hiding power and tinting strength was evaluated by coating on an opacity chart at a thickness of $150 \mu \mathrm{m}$ (Figure 6). The CIELAB 1976 method of determination of $\mathrm{L}^{*}, \mathrm{a}^{*}$ and $\mathrm{b}^{*}$ was employed to determine the hiding power and tinting strength of the colorants by comparison of values when coated on a board with a checkered, white and black background and the results are summarized in Tables 9. The colour difference has been quantified on the CIELAB based colour difference $\left(\mathrm{D} E_{\mathrm{ab}}\right)$, which is calculated using the Equation (1) [CIE 1986; CIE 2004; Ohno 2000]. For mass tone, the colour difference between the black and white region was found to be $\mathrm{D} E_{\mathrm{ab}}=10.8$. A lower value of $\mathrm{D} E_{\mathrm{ab}}$ (3.3) for mass tone on the black versus the white regions in the case of Ce0.8Ti0.05Pr0.15O2 sample indicates the ability of the dark-brown colorant to cover black and white regions uniformly well.

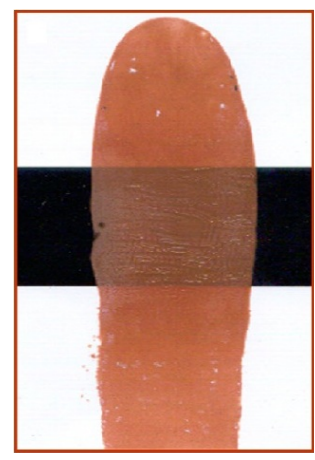

Figure 6. Photograph of hiding power of natural pigment.

Table 8. Comparison of colour value of natural pigment with synthetic pigment.

\begin{tabular}{ccc}
\hline & Synthetic pigment & Natural pigment \\
\hline $\mathrm{L}^{*}$ & 34.10 & 40.20 \\
$\mathrm{a}^{*}$ & 23.96 & 33.47 \\
$\mathrm{~b}^{*}$ & 15.85 & 25.92 \\
$\mathrm{DL}^{*}$ & & 6.10 \\
$\mathrm{Da}^{*}$ & 9.50 \\
$\mathrm{Db}^{*}$ & 10.06 \\
$\mathrm{DE}^{*}$ & & 15.12 \\
\hline
\end{tabular}

Table 9. Colour coordinate of the pigments after hiding power analysis on white and black surface.

\begin{tabular}{ccccc}
\hline Surface & $L^{*}$ & $a^{*}$ & $b^{*}$ & $D E_{a b}$ \\
\hline Black & 44.1 & 17.4 & 17.3 & 10.5 \\
White & 51.6 & 24.2 & 21.1 & 3.4 \\
\hline
\end{tabular}

$$
\mathrm{D} E_{\mathrm{ab}}=\left[\left(\mathrm{D} L^{*}\right)^{2}+\left(\mathrm{D} a^{*}\right)^{2}+\left(\mathrm{D} b^{*}\right)^{2}\right]^{1 / 2}
$$

\section{Conclusion}

Studied natural pigment has good chemical resistance and excellent mechanical properties. Naturally occurring pigments shows good performance properties compared with synthetic pigment, thus natural pigment can be good alternative for synthetic pigment.

\section{Acknowledgements}

Author acknowledges to UGC-SAP for providing financial support and also to sophisticated analytical instrument laboratory (SAIF, IIT. Bombay) for providing SEM and ICP-AES facility for analysis.

\section{REFERENCES}

[1] J. R. Barnett, S. Miller and E. Pearce, "Colour and Art: A Brief History of Pigments," Optics \& Laser Technology, Vol. 38, No. 4-6, 2006, pp. 445-453. doi:10.1016/i.optlastec.2005.06.005

[2] H. Berke, "The Invention of Blue and Purple Pigments in Ancient Times," Chemical Society Reviews, Vol. 36, No. 1, 2007, pp. 15-30. doi:10.1039/b606268g

[3] K. Bittler and W. Ostertag, "Developments in the Field of Inorganic Pigments," Angewandte Chemie International Edition in English, Vol. 19, No. 3, 1980, pp. 190-196. doi:10.1002/anie.198001901

[4] N. Eastaugh, V. Walsh, T. Chaplin and R. Siddall, "The Pigment Compendium, Optical Microscopy of Historical Pigments," Elsevier Butterworth-Heinemann, Oxford, 2004.

[5] Pharmacopeia of China, "Pharmacopoeia of China," People's Press, Beijing, 2005.

[6] T. Efferth, P. C. Li, V. S. Konkimalla and B. Kaina, "From Traditional Chinese Medicine to Rational Cancer Therapy," Trends in Molecular Medicine, Vol. 13, No. 8, 2007, pp. 353-361. doi:10.1016/j.molmed.2007.07.001

[7] A. Kumar, A. G. Nair, A.V. Reddy and A. N. Garg, "Bhasmas: Unique Ayurvedic Metallic-Herbal Preparations, Chemical Characterization," Biological Trace Element Research, Vol. 109, No. 3, 2006, pp. 231-254. doi:10.1385/BTER:109:3:231

[8] E. Ernst, "Toxic Heavy Metals and Undeclared Drugs in Asian Herbal Medicines," Trends in Pharmacological Sciences, Vol. 23, No. 3, 2002, pp. 136-139. doi:10.1016/S0165-6147(00)01972-6

[9] E. Lynch and R. Braithwaite, "A Review of the Clinical and Toxicological Aspects of "Traditional" (Herbal) Medicines Adulterated with Heavy Metals," Expert Opinion on Drug Safety, Vol. 4, No. 4, 2005, pp. 769-778. doi:10.1517/14740338.4.4.769

[10] K. Cooper, B. Noller, D. Connell, J. Yu, R. Sadler, Olszowy, H. Golding, G. Tinggi, U. Moore and M. R. Myers, "Public Health Risks from Heavy Metals and Metalloids," Journal of Toxicology and Environmental Health, Part A: Current Issues, Vol. 70, No. 19, 2007, pp. 1694- 
1699. doi:10.1080/15287390701434885

[11] E. Kang-Yum and S. H. Oransky, "Chinese Patent Medicine as a Potential Source of Mercury Poisoning," Veterinary \& Human Toxicology, Vol. 34, No. 3, 1992, pp. 235238.

[12] A. H. Liang and M. F. Shang, "General Situation of the Study on the Toxicity of Cinnabars," Zhongguo Zhong Yao Za Zhi, Vol. 30, No. 4, 2005, pp. 249-252.

[13] I. O. Ogunniyi, M. K. G. Vermaak and D. Groot, "Surface Characterization of Metallic Particles in Printed Circuit Board Comminution Fines and the Processing Implication," Journal of Minerals and Materials Characterization and Engineering, Vol. 11, No. 6, 2012, pp. 619-926.

[14] H. Hamid and F. Eric, "XPS \& FTIR Study of Adsorption
Characteristics Using Cationic and Anionic Collectors on Smithsonite," Journal of Minerals and Materials Characterization and Engineering, Vol. 5, No. 1, 2006, pp. 2145 .

[15] A. R. Gujar, N, Angusamy and G. V. Rajamanickam, "Characterization of Opaques off Konkan Coast Maharashtra, Central West Coast of India," Journal of Minerals and Materials Characterization and Engineering, Vol. 6, No. 1, 2007, pp. 53-67.

[16] S. A. Ibitoye and A. A. Afonja, "Characterization of Cold Briquetted Iron (CBI) by X-Ray Diffraction Technique," Journal of Minerals and Materials Characterization and Engineering, Vol. 7, No. 1, 2008, pp. 39-48. 